\title{
Multimodal Discourse on BRICS Produced by Diverse Stakeholders: Identifying Attitudes, Cultures and Perspectives
}

Anastasia A. Atabekova, ${ }^{+*}$ Rimma G. Gorbatenko, ${ }^{\dagger}$ and Tatyana V. Shoustikova ${ }^{\dagger}$

\section{Abstract}

The paper explores the conceptual vision of BRICS in the contemporary world. The study focuses on language and images that are used within BRICS-related institutional communication. We argue that the research is important because of the increasing impact of BRICS on the development of the multilateral and multipolar world. The research aims to offer preliminary considerations with regard to key topics, features and tools of multimodal discourse that comes from the BRICS nations and representatives of other international/regional organisations. This area has not been subject to academic analysis so far. This confirms the novelty of the present study.

The research material includes 600 image-text correlated items from BRICS official sources of information and from organisation and institutions, which are not affiliated with the BRICS and refer to national or international actors. The research combined theoretical analysis of literature, empirical investigation of materials within qualitative paradigm, through content-based analysis and manual coding on thematic and pragmatic criteria.

The findings reveal different approaches to BRICS that are introduced by different actors through specific coordination of verbal and visual tools, in explicit and implicit ways. The findings show that BRICS sources contain proportioned use of texts and photos of high-ranking official events, socio-cultural features of BRICS countries, and pictures of youth with regard to BRICS mission, values, goals, and policies. This strengthens the concept of equality and human rights provision in the modern world in general and leads to the understanding of the need to include the issues of youth rights and their equality on the BRICS agenda in an explicit way.

Keywords: BRICS; Multimodal Discourse; Language; Visualisation

\footnotetext{
' Peoples' Friendship University of Russia -RUDN University, Moscow, Russia

${ }^{*}$ Corresponding Author, Email: aaatabekova@gmail.com

(C) 2020 Atabekova et al. This is an Open Access article distributed under the terms of the Creative Commons Attribution License (http://creativecommons.org/licenses/by/2.0), which permits unrestricted use, distribution, and reproduction in any medium, provided the original work is properly cited.
} 


\section{Introduction}

The modern communication across countries intensively integrates various verbal and nonverbal tools. This lays grounds for studies of multimodal discourse analysis with regard to diverse settings and stakeholders. This refers to discursive practices in different institutional settings. The attention to the discourse on BRICS stems from the fact that BRICS plays a crucial role about deterrence policy within the global community that faces challenges of unipolar world advance.

The research framework takes into account the current move from the fourth generation under the dominance of the West to the fifth generation under the leading role of the East (Thussu, 2018). Further, the studies of the topic also bear in mind contemporary scholars' vision of the clash of civilisations and renewal of the world order (Huntington, 1996; Yakovets, 2000).

Human communication materialises the current state of affairs, prospective intentions and visions of diverse stakeholders within the international community. Therefore, narratives related to BRICS, reflect contamination of domestic and global socio-political cultures, bear strategic functions with regard to the world order and human rights development (van Noort, 2018). Thus, discourse on BRICS produced by different actors is relevant in terms of theoretical analysis and applied investigation of trends, best practices and challenges.

However, a scan through academic databases leads to the preliminary conclusion that the above topic has not been put on the agenda on academic research.

This perhaps confirms the present research relevance.

The research hypothesis assumes that BRICS nations and outside stakeholders might view and verbalise the BRICS phenomenon, actions, and its various prospectives in different ways. Seemingly, stakeholders' views in their respective multimodal discursive practices might be produced both explicitly and implicitly.
The goal of this research is to take initial steps in identifying and comparing key features, topics and tools of multimodal discourse that comes from the BRICS nations and representatives of other international/regional organisations.

The above goal is to be reached by implementing a number of objectives and respective activities, namely the following:

- study of literature to identify the significant trends of the research with regard to the topic under study;

- collection of visual and textual materials within the discourse on BRICS by its agencies and external actors, the formation of the above materials into a corpus;

- identification of major features with regard to text and visual tools correlation within the multimodal discourse on the topics under study;

- identification of major topics, concepts and related language units within discourse from BRICS and about BRICS;

- identification of visual content that goes along with the above topics within discourse from BRICS and about BRICS;

- interpretation of the data obtained with regard to the BRICS vision introduced both explicitly and implicitly.

This research begins with a review of the relevant literature. This follows a brief discussion of the materials and methods adopted in this research. Following this, it critically discusses the results.

\section{Literature Review}

The research starting point refers to the concept of multimodal discourse analysis that implies the study of language "in combination with other resources, such as images, scientific symbolism, gesture, action, music and sound" (O'Halloran, 2011).

The multimodal discourse has gone far beyond entertainment, enhances its areas, bridges past, present and future through coordinating words and images concerning historical and 
contemporary world stakeholders' opinions and aspirations (Faust et al., 2018).

The current studies within multimodal discourse cover a wide array of topics. Scholars traditionally explore visual and textual tools within advertising (Liu, 2019) and social mass media (Sachs-Hombach \& Thon, 2019). However, it should be recognised that multimodal discourse is often used for extremist purposes (Wignell et al., 2018). Pedagogical communication as subject to multimodal discourse analysis has become increasingly popular during the last decade (Firmansyah, 2018). Another trend refers to the research activities and their outcomes dissemination where visual and verbal tools serve to systematise knowledge (Norris, 2019), to specify the state of affairs in a particular area, for instance, financial issues (Höllerer et al., 2018), regional politics (Cvetkovic \& Pantic, 2018).

When turning to the topics related to BRICS phenomenon, first we have to acknowledge that the theme draws consistent attention from Academia. Researchers consider security issues (Abdenur, 2017), scientific collaboration (Finardi \& Buratti, 2016), business development (Ralston et al., 2015), youth promotion within human resources development (Zhao et al., 2018) within the BRICS alliance.

These studies reveal that scholars pay specific attention to discourses on BRICS, try to specify key concepts within communication linked to BRICS (Dwyer \& Arifon, 2019) and identify key topics that characterize major trends within BRICS members discourse (Duggan, 2018; Niu, 2018; Thompson \& Wet, 2018). Researchers also aim to consider speech strategies and style with regard to BRICS (van Noort, 2017) or a change of rhetoric on BRICS (Skak, 2019).

However, the multimodal environment of communication inside, and from BRICS members as well as from outside stakeholders is not at academic stake at present.

The above brief outline of current research trends related to discourse on BRICS issues confirms that the present research is timely, as its topic has not been specified by Academia so far.

\section{Materials and Methods}

As the research focused on the multimodal discourse, we decided to consider the diverse stakeholders' official communication sources presented in the digital information environment.

The research materials include texts and related images.

In line with the research hypothesis, goals and objectives, the starting point to select materials assumed that there should include different sources, including official sources of the BRICS as the international alliance, BRICS members' national sources.

Besides, it was necessary to take into the account discourses of international organisations of different nature (international political-economic organisations, international professional institutions, and international nongovernment organisations). Finally, it seemed relevant to consider mass-media of major stakeholders outside the BRICS membership, namely the USA and the UK.

The examples of the sources that were subject to the study are listed in the reference list.

The materials were organised into content image-text corpus.

A total of 600 image-text correlated items were subject to analysis. BRICS official sources of information produced the half of the corpus items. Three hundred items were taken from the BRICS official site (n.d.), BRICS Post (n.d.) and national mass media of BRICS Members.

The rest came from organisation and institutions, which do not have affiliation with the BRICS and refer to national or international actors.

Fifty samples represent the discourse of nongovernment organisations, that is national offices of NGO Amnesty International (USA) (n.d.). Fifty items came from international institutions that focus on analytical and forecast activities, that is the International Social Security 
Association (n.d.). Two hundred samples were found in the mass media sources, 130 were part of top USA (that is, The USA Today, n.d.; CNN, n.d.) and the UK (that is, The Times and Sunday Times, n.d.; BBC, n.d.) mass media, and seventy represented the EU mass media (Euro news, n.d.; European Cluster Collaboration Platform n.d.; Euroactive Plarform, n.d.).

The research procedures rested on the qualitative approach for several reasons. The analysis was conducted within the inductive pathway driven more by the textual and visual data itself rather than by some shaped and accepted theoretical provisions on the topic under study. This approach correlates with the goal of the research that aimed to identify congruent angles and topics. Furthermore, narrative analysis of grounded theory principles was implemented to identify contexts and developments of the discourse from BRICs and about BRICS. All the tools are constituent features of the qualitative paradigm in research (Mihas, 2019).

The study combined a theoretical analysis of literature and empirical activities.

The latter exploited manual coding and computer-based content analysis and used thematic and pragmatic criteria.

First, the authors acted as independent coders and manually specified the codes within the texts under study. Further, the codes were checked for cross-references and consistency. Only those codes that coincided in the analysis of all three coders were subject to further study.

Thematic criteria were related to the particular textual themes, including education, human rights, economic development and others. Their list initially amounted to 19 concepts.

The selected texts were organised into corpus. It was further processed through computer-based content analysis and resulted in five major conceptual slots.

Pragmatic criteria included positive / negative / interrogative / challenging attitudes of the text author to the theme under discussion. The parameters to distinguish the above followed the accepted definitions thereof (see, for, instance, discourse markers, n.d.; Furkó et al., 2019).

The next stage of the empirical analysis included the analysis of balanced visual and textual resources that were produced by BRICS bodies and by representatives of other institutional stakeholders, analysis of visual and language resources. The study of empirical visual data stood on qualitative coding analysis of visual sources, descriptive and interpretative methods (Mannay, 2016) to evaluate the balance and meaning of textual and visual tools within discourse production.

\section{Results and Discussion}

The section provides the results and interpretation of the study on the themes, contents and coordination between the texts and images within BRICS discourse and discourse on BRICS topics produced by stakeholders outside the alliance.

First, we consider the textual and visual data produced by official BRICS sources and then move to information and comments on BRICS members' national approach to BRICS positioning in the contemporary world.

Next, we consider the data from international institutions, that is international, regional political organisations, and non-governmental institutions.

Finally, we offer a brief tour across BRICS positions in the mass media of those countries that oppose and stand away from the BRICS.

\section{BRICS: Multimodal Discourse}

The items from the BRICS official sources cover the following significant issues: political cooperation, economy, society, education, world development.

The study made it possible to identify the list of subtopics and their related concepts that are verbalised through the text, and related visual support, see Table 1. 


\begin{tabular}{|c|c|c|}
\hline Major Slots & $\begin{array}{l}\text { Verbally Represented Concepts } \\
\text { Within Respective Slots Frames }\end{array}$ & Visual Support \\
\hline Politics & $\begin{array}{l}\text { Unity, cooperation, coordination, } \\
\text { strategic partnership, new } \\
\text { development paradigm, safeguard } \\
\text { world peace, (to boost) dialogue, } \\
\text { gain influence, growth story, growth } \\
\text { potential, alliance }\end{array}$ & $\begin{array}{l}\text { photos of BRICS leaders or top- } \\
\text { ranking officials } \\
\text { national flags } \\
\text { images of BRICS countries } \\
\text { nationals in traditional cultural or } \\
\text { modern dressings } \\
\end{array}$ \\
\hline Economy & $\begin{array}{l}\text { Open world economy, powerful } \\
\text { force against protectionism, } \\
\text { investment-led trade }\end{array}$ & $\begin{array}{l}\text { photos related to a particular area } \\
\text { (military and technology } \\
\text { cooperation, pictures of industrial } \\
\text { and agricultural infrastructure, } \\
\text { images of BRICS national } \\
\text { currencies, etc.) }\end{array}$ \\
\hline $\begin{array}{l}\text { Global } \\
\text { Governance }\end{array}$ & $\begin{array}{l}\text { multilateralism, new world actors in } \\
\text { the world, (that has established } \\
\text { powers), new world view }\end{array}$ & $\begin{array}{l}\text { photos related to a particular area } \\
\text { (military and technology } \\
\text { cooperation, pictures of industrial } \\
\text { and agricultural infrastructure, } \\
\text { images of BRICS national } \\
\text { currencies, etc.) }\end{array}$ \\
\hline Society & $\begin{array}{l}\text { People's welfare, education, health, } \\
\text { ecology, culture, industrial } \\
\text { development }\end{array}$ & $\begin{array}{l}\text { males and females from BRICS } \\
\text { countries attending events related } \\
\text { to mentioned settings, youth } \\
\text { audience representatives }\end{array}$ \\
\hline Equality & $\begin{array}{l}\text { The concept within the framework } \\
\text { of gender and age, economic issues, } \\
\text { social insurance, education, } \\
\text { healthcare }\end{array}$ & $\begin{array}{l}\text { males and females from BRICS } \\
\text { countries within the mentioned } \\
\text { settings, youth audience } \\
\text { representatives }\end{array}$ \\
\hline \multicolumn{3}{|c|}{ Source: Compiled by the Authors } \\
\hline
\end{tabular}

The authors drafted this Table 1 on grounds of the findings of the content analysis of textual and visual tools.

The official mass media of BRICS countries follow the style of the joint BRICS sources. However, they mostly visualise national contexts of their country activities within the BRICS.

Thus, The Times of India (n.d.) uses the following language to verbalise the major concepts:

- Fastest-growing economies

- a large influence on regional affairs

- nearly half the world's population

- the growth of BRICS

- non-interference, equality and mutual benefit
RIA NEWS (n.d.) publishes consistent content on BRICS-related topics within both national, BRICSbased bilateral and BRICS-related international contexts.

Apart from topic topic-related language, the brief reports use the following most generalised concepts that are identified through the information about the summit between President Vladimir Putin and Prime Minister Narendra Modi within Eastern Economic Forum 2019:

- collaboration

- strengthening the BRICS position on the international markets

- strategic partnership

- mutual benefits 
- a common view at world challenges

(Partnership, global issues, trade: Putin and Modi held talks, 2019).

The study of BRICS sources confirms that their discourses aim to foster the members' objectives of equal multifaceted partnership in security, economy, culture and education. This is verbalised through respective wording. Moreover, the concept of equality runs like a red thread through both the texts and the pictures. The images of national leaders, flags, BRICS countries nationals are coordinated in terms of size and position in the picture. What is more, the preliminary statistics shows that there is a balance of pictures in terms of their thematic content.

The photos of BRICS leaders and that ones, related to the countries' economic, social and cultural development are proportional. Further it should be mentioned that apart from the BRICS leaders' photos, the alliance sources consistently use the images of young males and females when discussing society and equity issues within the framework of people's welfare, education, health, ecology, culture gender and age, social insurance, healthcare.

This leads to the assumption that the BRICS members view its mission and values as those associated with equality concept and its verbal content. Scholars agree that equality in a moral sense is found in fairness and justice with regard to human rights and opportunities in various societal dimensions (Lamorgese \& Geneletti, 2015; Srinivasan \& Jino, 2016).

As for BRICS, scholars traditionally focus on sovereign equality and reform of global order and governance (Zondi, 2019) and reveal this idea in the strategic narratives of BRICS (van Noort, 2019). However, the present study leads to the preliminary statement that BRICS multimodal discourse implicitly advances the idea of human equality, and advocate for equal human rights in general and that of youth, in particular. The choice of female and male youth images in the BRICS multimodal discourse confirms this statement. Moreover, there is a coordinated balance between pictures and texts with regard to youth development in various areas, including education, culture, health, employment.

\section{Discourse on BRICS from International Institutions}

The Euronews (n.d.) reports also combine info on summits with analytics. Photos of official character support the texts: leaders, meetings sites and participants, etc.

The European Cluster Collaboration Platform (n.d.), the Euractive (n.d.) an independent panEuropean media network specialised in EU policies follow the official neutral style of visual support of critical verbal representation of the EU views on BRICS as a strong emerging market and industry phenomenon. However, the selected language units and visual images hint that this group, however, faces consistent social, economic challenges, that are verbally marked by a number of rhetoric questions.

As for the international non-governmental organisations, the situation differs. This, the International Social Security Association (n.d.) uses neutral rhetoric and data provision, text is supported by the BRICS Leaders photos and infographic data. NGO Amnesty International (USA) (n.d.) publishes texts that are highly criticising text is supported by the neutral BRICS Leaders photos.

- human rights violation

- unprecedented harassment

- extrajudicial executions

- unjust prison sentence

- hate crimes against marginalised communities.

The brief tour across the official EU sources, international non-governmental and professional institutions makes it possible to state that they use strong criticizing rhetoric on BRICS and use either contrastive culturally featured pictures of BRICS stories and nationals or official pictures of BRICS summits.

\section{Multimodal Discourse on BRICS from National Mass Media Outside BRICS}

The official mass media from the USA and UK sources provide information on BRICS summits, 
high-ranking meetings and analytics, related mostly to security topics or economic state of affairs.

The research results reveal that the above info pieces differ in terms of their discursive practice

Some publications include critical notes on political, economic, security, extremism, and poverty challenges. The most used concepts and related language units reveal the author's critical attitude to the subjects under evaluation:

- serious problems /high rate of inflation

- ingrained corruption

- industrial unrest/overdependence on oil and natural gas

- civil unrest/popular discontent

The above data from the Times is supported by bright photos of people in national Indian dresses (Atherton, 2012) to produce a contrast between coloured pictures of attractive women and strongly negative wording.

There might be another approach to unite words and pictures when discussing BRICS. The text can be built on contradicting concepts "hopedisappointment", "business-stopped", and "construction- turmoil" about BRICS economy. Pictures of digger machines that stand on a city street and do not work support these assertions (Lea, 2015).

There might be another way to introduce BRICS activities within the world framework. Thus, the BBC takes the way of mixing the direct and indirect speech of BRICS leaders and the US President Donald Trump. The citations are diluted by pieces of neutral information about related events. As for visual support, the BBC takes a more official stance in terms of photos among which images of the BRICS leaders (BRICS back 'open world economy' that benefits all nations, 2018) combine with modern looks of BRICS countries nationals (Four things to watch at the BRICS summit, 2017). However, the latter link $B B C$ reports introduce less formal pictures.

The USA Today follow neutral informative style, its analytics on security topics and social challenges are accompanied by official photos of the BRICS leaders (Nirmala, 2016)
Similarly, the topics on BRICS are introduced by CNN reporters, which combine speeches by experts on BRICS with photos of BRICS leaders and iconographies on economic issues (Joy, 2013).

The results of the study confirm that the investigation of communication trends and features on and within BRICS integrate past legacies and bear undated relevance (Bharthur, 2018).

The research findings confirm the earlier data that underlines that BRICS countries use visual and verbal tools to build and introduce to the international community a collective vision of BRICS, set forth justification discourses that are most explicitly introduced at BRICS summits, through the New Development Bank initiatives, BRICS Network University policies and activities, social media (Dwyer \& Arifon, 2019).

The obtained data also go in line with previous studies on coordination of textual and visual tools in multimodal discourse (Ledin \& Machin, 2019).

However, the findings reveal that visual tools in discourses produced by BRICS specify and foster the ideas that are not verbalised explicitly and are beyond the direct language means that introduce the BRICS frontline mission and goals. The images that sources of BRICS members use refer to global human values, the concept of equality in all societal dimensions across different parts of the world. This confirms the ethical praxis of multimodal discourse (Roderick, 2018) with regard to BRICS communication and positioning.

The proportioned use of youth pictures implicitly (in support for explicit wordings) refers the audiences to the concept of equal rights of all populations, including youth that is viewed by scholars as one of potentially vulnerable population (De Chesnay \& Anderson, 2019). As it was mentioned earlier, the research has found a coordinated balance between pictures and texts with regard to youth access to facilities and development in various areas, including education, culture, health, employment. 
However, one more point should be mentioned in relation to the above. The study of the texts and images reveal a great interest in education issues. Meanwhile, the question of language policy role is not discussed yet, though the population of BRICS countries speaks three languages that are the UNO official languages. Bearing in mind the above, further discussion of BRICS prospects could focus on multilingual training for non-language students. Scholars consistently mention the importance of this topic for international higher education and underline a particular importance of the issue for non-language students (Belenkova et al., 2018).

\section{Conclusion}

The research findings confirmed the hypothesis that BRICS nations and outside stakeholders view and verbalise their attitude to the BRICS policies and activities, in different ways due to stakeholders' clashing goals and aspirations. Moreover, the study outcomes have proved that the stakeholders' views in their respective multimodal discursive are produced both explicitly and implicitly.

The research has made it possible to specify and distinguish concepts and images of multimodal discourse that comes from the BRICS nations and representatives of other international/regional organisations and countries outside BRICS.

It has been found that socio-cultural features of a particular nation as BRICS member are used to support authors' opinions.

The research results lead to the identification of ways through which linguistic and visual tools are used to mirror and reflect on BRICS MemberStates activities within the international landscape. The findings show how diverse stakeholders affiliated with different sociopolitical and cultural background use language and visualisation to shape international public perceptions of BRICS.

The data obtained makes it possible to draft preliminary recommendations to those involved in raising awareness of BRICS goals, with regard to language and visualisation tools for information design and its promotion. To our mind, a more consistent policy should be implemented in terms of BRICS youth representation within the global landscape, both verbally and visually.

Earlier in the research, it has been specified that the balanced proportioned use of youth pictures across the BRICS sources operate as an implicit contribution to explicit language on human values highly appreciated and promoted by BRICS.

This puts the BRICS agenda in line with the UNO 2030 agenda. Moreover, the discovered features of BRICS multimodal discourse remind the audiences of the youth potential in the civilisation development. Further, these features lead to the public understanding of the need to include the issue of youth rights and their equality on the BRICS agenda in an understandable way. Meanwhile, currently BRICS official declarations and statements do not mention youth and minors and focus on general political, security, economic, social goals, and mention the importance and prospects of people-to-people exchanges.

\section{References}

Abdenur, A.E. (2017). Can the BRICS cooperate in international security? International Organisations Research Journal, 12(3), 73-93.

Atherton, M. (2012). Should you stick with the BRICs? Retrieved on 8 September 2019 from, https://www.thetimes.co.uk/article/shouldyou-stick-with-the-brics-537cqk072hb

$B B C$ (n.d.). Retrieved on 10 September 2019 from, https://www.bbc.com

Belenkova, N.M., Kruse, I.I., Davtyan, V.V., \& Wydra, D. (2018). Language for students without interest in languages: Challenges of foreign language grammar. XLinguae, 11 (1), 284-293.

Bharthur, S. (2018). New world information and communication order and BRICS: legacies and relevance. Global Media and China, 3(2), 113116.

BRICS back 'open world economy' that benefits all nations (2018). Retrieved on 10 September 2019 from, 
https://www.bbc.com/news/business44973352

BRICS official site (n.d.). Retrieved on 15 September 2019 from, http://infobrics.org/news/summits/?page $=4$

Brics Post (n.d.). Retrieved on 15 September 2019 from, https://www.thebricspost.com

CNN (n.d.). Retrieved on 15 September 2019 from, https://edition.cnn.com

Cvetkovic, I., \& Pantic, M. (2018). Multimodal Discursivity: Framing European Union Borders in Live-Blogs. Journal of Communication Inquiry, 42(4), 318-339.

De Chesnay, M., \& Anderson, B. (2019). Caring for the vulnerable. Burlington, Massachusetts: Jones \& Bartlett Learning.

Discourse markers (n.d.). Retrieved on 8 September 2019 from, https://dictionary.cambridge.org/grammar/briti sh-grammar/discourse-markers-so-right-okay

Duggan, N. (2018). 8 The BRICS and nontraditional security. In BRICS and Global Governance (pp. 150-167). Abingdon: Routledge.

Dwyer, T., \& Arifon, O. (2019). Recognition and transformation: Beyond media discourses on the BRICS. Global Media and Communication, 15(1), 27-47.

Euroactive platform (n.d.). Retrieved on 8 September 2019 from, https://euractiv.com

Euronews (n.d.). Retrieved on 8 September 2019 from,

https://www.euronews.com/tag/brics-summit

European Cluster Collaboration Platform (n.d.). Retrieved on 8 September 2019 from, https://www.clustercollaboration.eu/tags/brics

Faust, M., Schneider, F., Herdin, T., Ji, D., Negro, G., Zhou, T., ... \& de Oliveira Nascimento, A. K. (2018). BRICS as formation to study visual online communication?: A dialogue on historical origins, perspectives on theory and future directions. China Media Research, 14(2), 85-86.

Finardi, U., \& Buratti, A. (2016). Scientific collaboration framework of BRICS countries: an analysis of international co-authorship. Scientometrics, 109(1), 433-446.

Firmansyah, M. B. (2018). Multimodal conception in learning. ISLLAC: Journal of Intensive Studies on Language, Literature, Art, and Culture, 2(1), 40-44.

Four things to watch at the BRICS summit (2017). Retrieved on 8 September 2019 from, https://www.bbc.com/news/business41144276

Furkó, P., Kertész, A., \& Abuczki, Á. (2019). Discourse markers in different types of reporting. In Indirect Reports and Pragmatics in the World Languages (pp. 243-276). New York: Springer, Cham.

Höllerer, M.A., Jancsary, D., \& Grafström, M. (2018). 'A picture is worth a thousand words': Multimodal sensemaking of the global financial crisis. Organization Studies, 39(5-6), 617-644.

Huntington, S. (1996). The clash of civilizations and the remaking of world order. New York: Simon and Shuster.

International Social Security Association (n.d.). Retrieved on 8 September 2019 from, https://www.issa.int/en/topics/brics/introducti on

Joy, O. (2013). Building on 'BRICS': The next emerging economies. Retrieved on 9 September 2019 from, https://edition.cnn.com/2013/03/27/business/ brics-civets-emerging-markets/index.html Lamorgese, L., \& Geneletti, D. (2015). Equity in sustainability assessment: a conceptual framework. In A. Morrison-Saunders, J. Pope, A. Bond (Eds.), Handbook of sustainability assessment, research handbooks on impact assessment. (pp. 57-76). Cheltenham: Edward Elgar.

Lea, R. (2015). Digging beneath the surface of Britain and the BRICS, it's time to get out the $J C B$. Retrieved on 10 September 2019 from, https://www.thetimes.co.uk/article/diggingbeneath-the-surface-of-britain-and-the-bricsits-time-to-get-out-the-jcb-frppd35b232 
Ledin, P., \& Machin, D. (2019). Doing critical discourse studies with multimodality: from metafunctions to materiality. Critical Discourse Studies, 16(5), 497-513.

Liu, S. (2019). A multimodal discourse analysis of the interactive meaning in public service advertisement. Journal of Advances in Linguistics, 10, 1523-1534.

Mannay, D. (2016) Visual, narrative and creative research methods. Application, Reflection and Ethics. Abingdon: Routledge.

Mihas, P. (2019). Qualitative data analysis. In Oxford Research Encyclopedia of Education. Oxfrod: Oxfrod University Press.

NGO Amnesty International (USA) (n.d.). Retrieved on 10 September 2019 from, https://www.amnestyusa.org/pressreleases/brics-nations-must-put-human-rightsfirst/

Nirmala, G. (2016). BRICS leaders vow to speed global recovery, fight terrorism. Retrieved on 8 September 2019 from, https://www.usatoday.com/story/news/world/ 2016/10/16/brics-leaders-vow-speed-globalrecovery-fight-terrorism/92199438/

Niu, H. (2018). The BRICS agenda in the AsiaPacific region. In BRICS and Global Governance (pp. 208-222). Abingdon: Routledge.

Norris, S. (2019). Systematically working with multimodal data: Research methods in multimodal discourse analysis. Hoboken, New Jersey: Wiley-Blackwell.

O`Halloran, K.L. (2011). Multimodal discourse analysis. In K. Hyland and B.Paltridge (eds). Companion to Discourse. London and New York: Continuum.

Partnership, global issues, trade: Putin and Modi held talks (2019). Retrieved on 10 September 2019 from, https://ria.ru/20190904/1558287807.html

Ralston, D.A., Egri, C.P., Karam, C.M., Naoumova, I., Srinivasan, N., Casado, T., ... \& Alas, R. (2015). The triple-bottom-line of corporate responsibility: Assessing the attitudes of present and future business professionals across the BRICs. Asia Pacific Journal of Management, 32(1), 145-179.

RIA NEWS (n.d.). Retrieved on 10 September 2019 from, https://ria.ru/organization_BRIKS

Roderick, I. (2018). Multimodal critical discourse analysis as ethical praxis. Critical Discourse Studies, 15(2), 154-168.

Sachs-Hombach, K., \& Thon, J.N. (2019). Introduction: Multimodal Media. Poetics Today, 40(2), 183-187.

Srinivasan, S., \& Jino, M.J. (2016). Social protection: a human right to promote social justice and equity. In Social Development and Social Work Perspectives on Social Protection (pp. 72-95). Abingdon: Routledge.

Skak, M. (2019). Russia 9 and the BRICS. The International Political Economy of the BRICS, 150.

The Times and Sunday Times (n.d.). Retrieved on 8 September 2019 from, https://www.thetimes.co.uk/

The USA Today (n.d.). Retrieved on 8 September 2019 from, https://www.usatoday.com/

The Times of India (n.d.) Retrieved on 8

September 2019 from, https://timesofindia.indiatimes.com/topic/BRIC $\mathrm{S}$

Thompson, L., \& Wet, P.T.D. (2018). BRICS civil society initiatives: towards the inclusion of affected communities in collective development? Third World Thematics: A TWQ Journal, 3(5-6), 745-764.

Thussu, D. (2018). BRI: Bridging or breaking BRICS? Global Media and China, 3(2), 117-122.

van Noort, C. (2017). Study of strategic narratives: The case of BRICS. Politics and Governance, 5(3), 121-129.

van Noort, C. (2018). BRICS issue-narrative on culture: strategic or trivial? International Journal of Cultural Policy, 24(6), 786-797.

van Noort, C. (2019). The Construction of power in the strategic narratives of the BRICS. Global Society, 33(4), 462-478 
Wignell, P., Chai, K., Tan, S., O’Halloran, K., \& Lange, R. (2018). Natural language understanding and multimodal discourse analysis for interpreting extremist communications and the re-use of these materials online. Terrorism and Political Violence, 31(3), 454-474.

Yakovets, Yu. (2000). The Past and the Future of Civilizations. Lewiston-Queenston Lampeter: The Edwin Mellen Press.

Zhao, X., Li, M., Huang, M., \& Sokolov, A. (Eds.). (2018). BRICS Innovative Competitiveness Report 2017. New York: Springer.
Zondi, S. (2019). The BRICS and the transformation of global governance: $A$ decolonial perspective. Africa Insight, 48(4), 7386.

\section{Acknowledgements}

The publication has been prepared with support of the RUDN University programme under 5-100 Russian Academic Excellence Programme, research project number 090512 -1- 274. 